\title{
Asterocheres hirsutus, a new species of parasitic copepod (Siphonostomatoida: Asterocheridae) associated with an Antarctic hexactinellid sponge
}

Received: 11 August 2004 / Revised: 19 June 2005/ Accepted: 4 July 2005 / Published online: 6 September 2005

(C) Springer-Verlag and AWI 2005

\begin{abstract}
The asterocherid siphonostomatoid copepod Asterocheres hirsutus, a new species, is described from a hexactinellid sponge of the genus Rossella Carter collected during the Polastern cruise ANT XVII/3, off South Shetland Islands. The distinctive features of this new species are: a female with 21 -segmented and a male with 17-segmented antennules, praecoxal endite of maxillule more than four times longer than palp and the ornamentation of the posterior surface of legs 1-4. A detailed description of both sexes is presented.
\end{abstract}

Keywords Asterocherid siphonostomatoid · Hexactinellid sponge $\cdot$ Symbiosis $\cdot$ Antarctica

\section{Introduction}

The Asterocheridae Giesbrecht, 1899 is the largest family of the siphonostomatoid copepods with about 200 species. This family exploits the potential diversity that exists among invertebrate organisms as hosts and can be found associated with molluscs, bryozoans, corals, echinoderms, polychaetes, sponges and ascidians (Ivanenko and Smurov 1997; Johnsson and Bustamante 1997).

Among copepods of the family Asterocheridae, the type-genus Asterocheres Boeck, 1859 is the most speciose with about $33 \%$ of the known species, $56 \%$ of which have been found associated with sponges. Despite the fact that the sponges are one of the groups that dominate many of the Antarctic shelf benthic communities (Galéron et al. 1992), only one species of Asterocheres associated with sponges is known in this area.

Communicated by R.M. Kristensen

Mㄹ E. Bandera · M. Conradi · P. J. López-González Biodiversidad y Ecología de Invertebrados Marinos, Departamento de Fisiología y Zoología, Facultad de Biología, Universidad de Sevilla, Reina Mercedes 6, 41012 Sevilla, Spain

E-mail: ebandera@us.es
Research on the biodiversity in the Southern Ocean has increased greatly in recent decades (Arntz 1997). Nevertheless, the research effort directed at the different taxonomic groups has not been uniform. Some surveys have been carried out within the framework of international programs, such as EASIZ (Ecology of the Antarctic Sea Ice Zone), in order to improve the understanding of certain, as yet poorly known, groups in the Southern Ocean. These expeditions gave the authors the opportunity to study some fauna associated to Antarctic invertebrates. In the present work we describe a new species of Asterocheres found associated with a hexactinellid sponge of the genus Rossella Carter.

\section{Methods}

Sponges infected with parasitic copepods were collected on the R/V Polarstern cruise ANT XVII/3 (EASIZ III) sponsored by the Alfred Wegener Institut für Polar- und Meeresforschung, Bremerhaven, during the austral summer of 2000 . The material was collected with the aid of Agassiz trawl, sorted, labelled and fixed on board. Symbiotic fauna was obtained by pouring the wash water through a $100 \mu \mathrm{m}$ mesh net. The copepods were finally recovered from the sediment retained and preserved in $70 \%$ ethanol.

Selected specimens were stained with Chlorazole black E (Sigma ${ }^{\circledR}$ C-1144), dissected in lactic acid and examined as temporary mounts in lactophenol. All figures were drawn with the aid of a camera lucida on a Leica DMLB differential interference microscope. In order to detect minute details, some specimens were prepared and photographed using a PHILIPS XL30 SEM. All appendage segments and setation elements are named and numbered using the system established by Huys and Boxshall (1991).

Material examined in the present paper is deposited in the Zoologisches Institut und Zoologisches 
Museum in Hamburg (ZMH) and in the collection of Biodiversidad y Ecología de Invertebrados Marinos research group of the University of Seville (BEIM).

\section{Results}

Asterocheres hirsutus sp. nov (Figs. 1, 2, 3, 4, 5)

Material examined

Sixty-three females and nine males associated with the hexactinellid sponge Rossella sp. collected from the
Polarstern cruise ANT-XVII/3 (EASIZ-III), off South Shetland (Antarctica), stn. 178.2, 61 ${ }^{\circ} 58.50^{\prime} \mathrm{S} 60^{\circ} 19.70^{\prime} \mathrm{W}$, 804-930 m depth, 2 May 2000. The holotype, 1 adult female (K 40872), allotype, 1 adult male (K 40873), paratypes, 20 females and 4 males (K 40874) have been deposited in the $\mathrm{ZMH}$. The rest of the material is deposited in the collection of BEIM (COP-504).

\section{Adult female}

Body cyclopiform (Figs. 1, 2), slender with cephalothorax oval and cyclindrical urosome (Figs. 1a, b.). Mean
Fig. 1 Asterocheres hirsutus sp. nov. Female, a, habitus, dorsal; b, habitus, lateral; c, urosome, ventral; d, fifth leg, dorsal; $\mathbf{e}$, second antenna

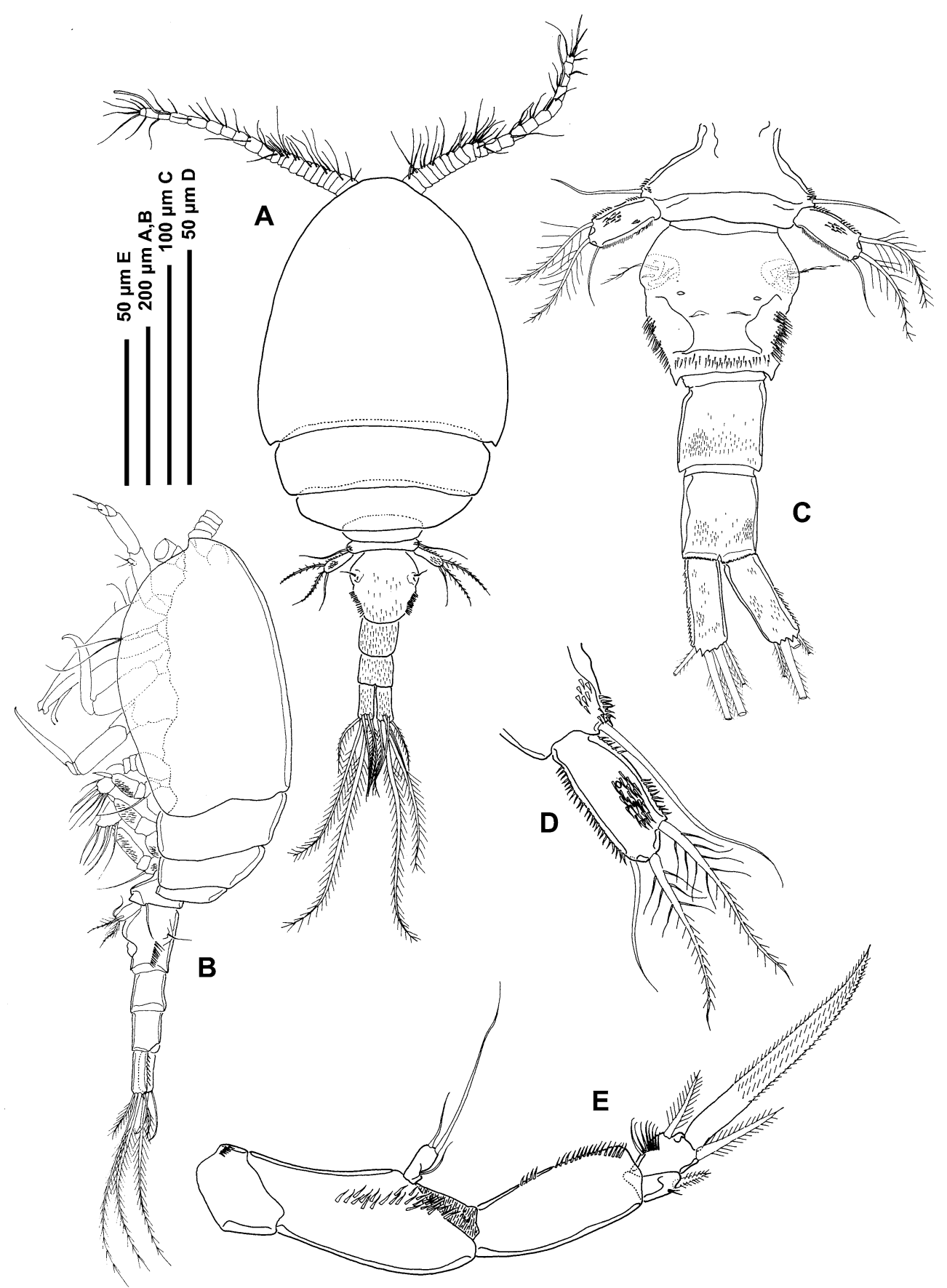


Fig. 2 Asterocheres hirsutus sp. nov. Female, a, antennule; b, detail of the compound segment 9 (IX-XII) of the antennule; $\mathbf{c}$, oral cone; $\mathbf{d}$, mandible; $\mathbf{e}$, tip of mandibular stylet; f, maxillule; $\mathbf{g}$, maxilla; $\mathbf{h}$, maxilliped

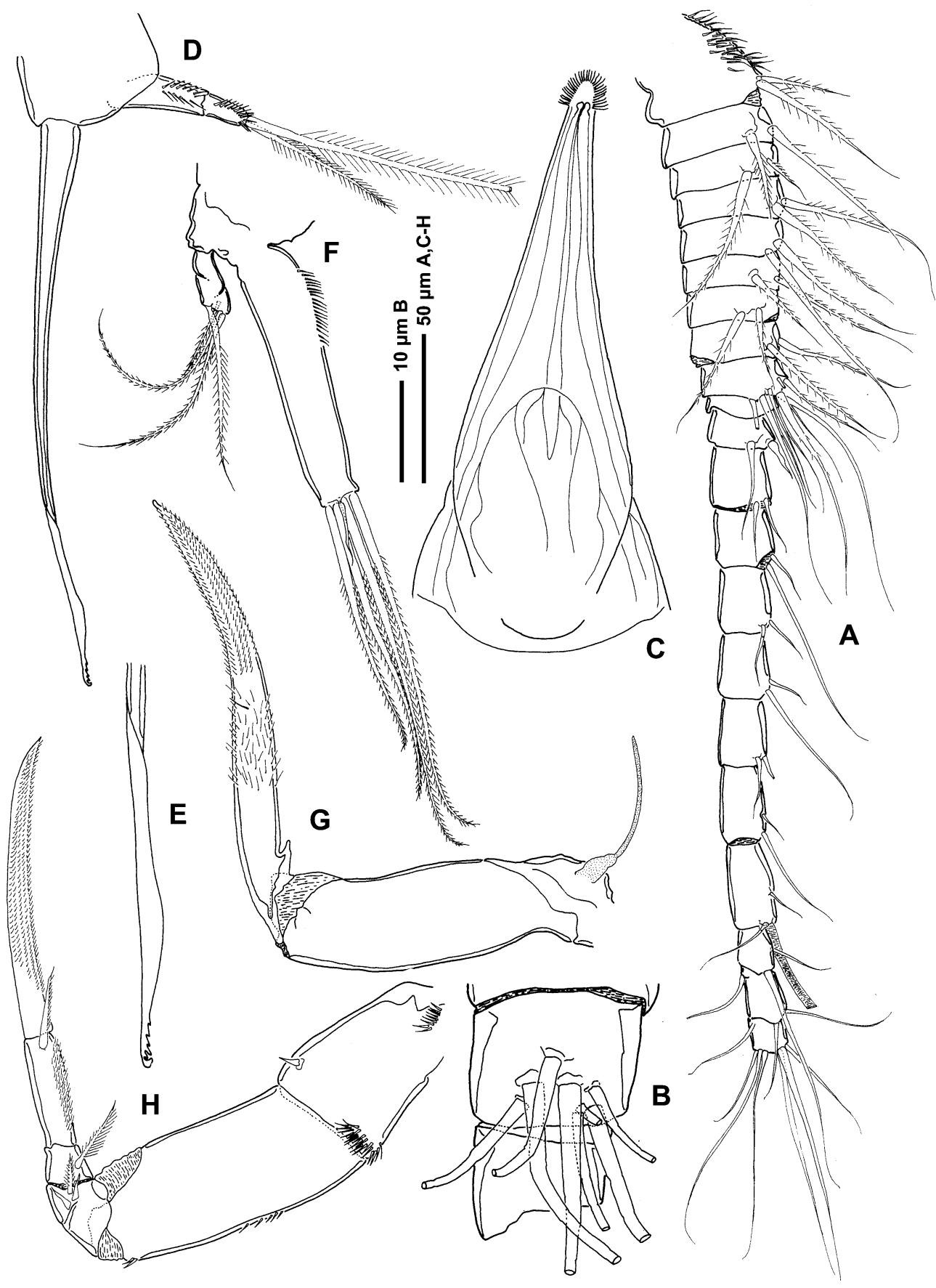

body length $820 \mu \mathrm{m}$; with range of 759-875 $\mu \mathrm{m}$ (based on three specimens). Ratio of length to width of prosome 1.44: 1. Ratio of length of prosome to that of urosome, 2:1. Prosome comprising the cephalothorax fully incorporating first pedigerous somite and three free pedigerous somites. Somite bearing leg 4 is much smaller and narrower than preceding ones.

Urosome 4-segmented comprising leg 5-bearing somite, genital double-somite and two free abdominal somites. Somite bearing leg 5 (Fig. 1c) wider than long, $40 \times 80 \mu \mathrm{m}$ with some spinules on dorsal surface. Genital double-somite as long as wide, bearing genital apertures, paired gonopores located laterally. Lateral margin of double-somite ornamented with fringe of long spinules located about midway along double-somite, posterior to gonopores level (Fig. 1a, b, c; 4 e, g). Each genital area armed with one plumose seta and one spiniform element. Two postgenital somites subquadrate (Fig. 1c). Dorsal surface of free abdominal somites and posterior part of double-somite ornamented with tiny spinules.

Caudal rami 2.5 times longer than wide (Figs. 1c, 4e), armed with six setae. Two medial dorsal naked setae, outer $100 \mu \mathrm{m}$ long and inner $96 \mu \mathrm{m}$. Four terminal setae: outermost terminal setae, $90 \mu \mathrm{m}$; innermost, $94 \mu \mathrm{m}$, both 
Fig. 3 Asterocheres hirsutus sp. nov. Female, a, leg 1; b, leg 2; c, leg 3 ; d, leg 4
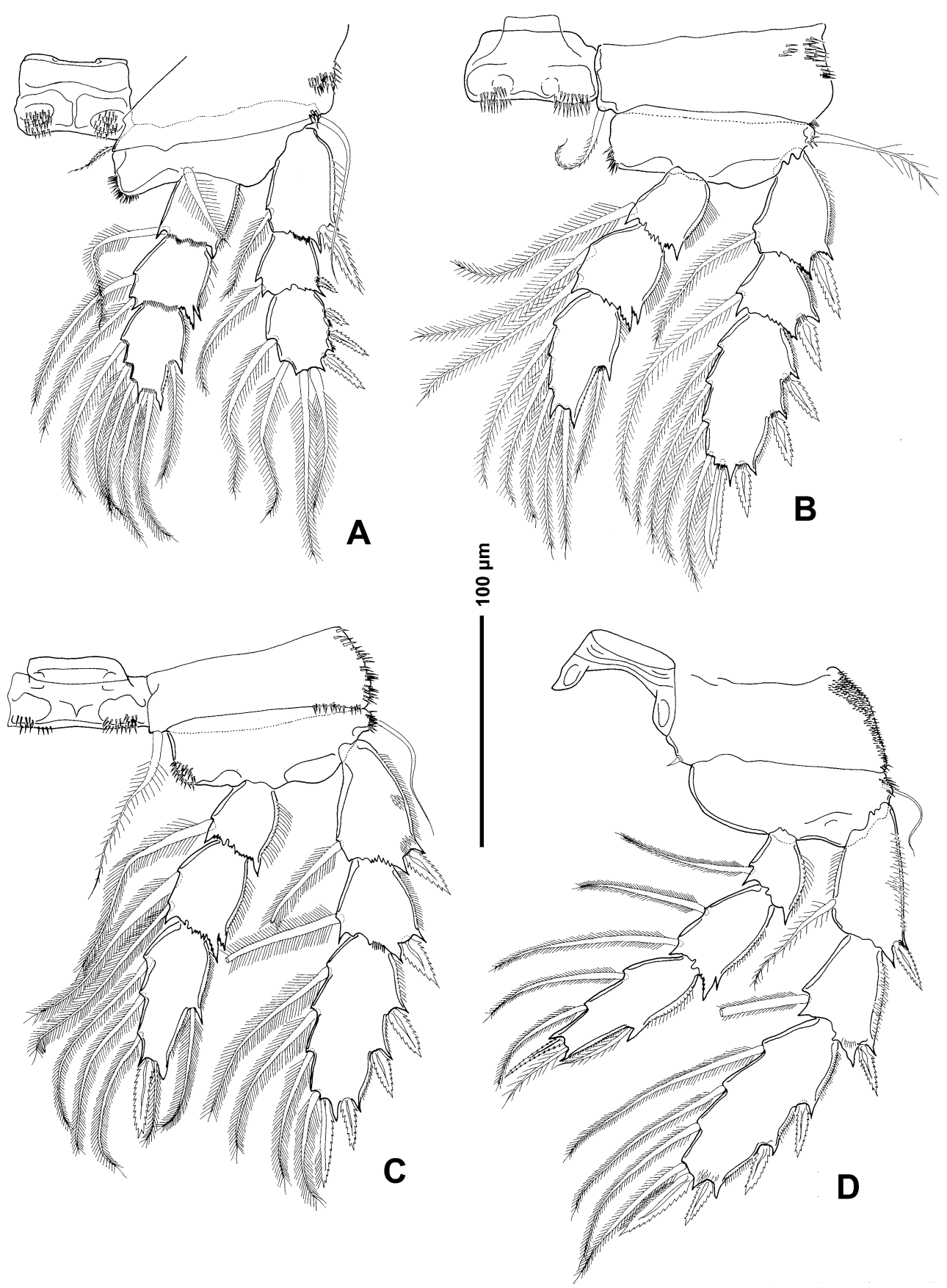

with setules on inner side; and two median terminal plumose setae, $210 \mu \mathrm{m}$ (outer) and $300 \mu \mathrm{m}$ (inner). Surface of caudal ramus ornamented with minute spinules.

Antennule $369 \mu \mathrm{m}$ long and consist of 21 articulating segments (Fig. 2a). Segmental fusion pattern as ollows: 1(I), 2(II), 3(III), 4(IV), 5(V), 6(VI), 7(VII), 8(VIII), 9(IX-XII), 10(XIII), 11(XIV), 12(XV), 13(XVI), 14(XVII), 15(XVIII), 16(XIX), 17(XX), 18(XXI), 19(XXII-XXIII), 20(XXIV-XXV), 21(XXVIXXVIII). Lengths $(\mu \mathrm{m})$ of its segments are as follows (measured along their posterior margin), 21 (30 along anterior margin), 14, 12, 10, 14, 10, 12, 14, 12, 7, 10, 21.8, 23.6, 18.7, 23.4, 23.4, 23.4, 26.5, 29.6, 15.6, 17, 10. Segments 1-8 each with 2 setae; segment 9 with 8 setae; segment 10-17 each with 2 setae; segment 18 with 2 setae plus an aesthetasc; segment 19 with 2 setae; segment 20 with 3 setae; segment 21 with 7 setae. Segment 10 (XIII) reduced, partly overlapped by distal expansion of compound segment 9 (IX-XII) (Fig. 2b).

Antenna biramous and $180 \mu \mathrm{m}$ long excluding terminal claw (Fig. 1e). Small unarmed coxa with tuft of spinules. Elongated unarmed basis ornamented with fine spinule row and bearing 1-segmented exopodite and 
long 3-segmented endopodite. Exopod small, longer than wide armed with one lateral and two unequal apical setae, the longer three times longer than the small one. First segment of endopodite elongate, $61 \times 26.5 \mu \mathrm{m}$, unarmed but ornamented with rows of spinules; second segment produced distally on medial side but articulating with third segment proximally on lateral side and armed with one plumose short seta and two setules at base. Third segment armed with two plumose setae and large distal claw, $93 \mu \mathrm{m}$ long, and also ornamented with rows of fine spinules shortened in length.

Mandible with 2-segmented palp and stylet-like gnathobase (Fig. 2D). Stylet $192 \mu \mathrm{m}$ long, with subapical denticulate margin (Fig. 2e). First segment of palp slender, unarmed but ornamented with a row of spinules laterally; second segment half length of first one, with 2 terminal unequal plumose setae. Stylet located in oral cone. Oral cone (Fig. 2c, 4a,b) formed by labrum and labium joined laterally, $195 \mu \mathrm{m}$ long, reaching intercoxal sclerite of leg 1 . Cone broad proximally and tapering distally. Labrum almost completely covers labium. Tip of labrum curved posteriorly, with ribbed surface and dense hair-like ornamentation.

Maxillule bilobed (Figs. 2f, 4b); praecoxal endite more than four times longer than palp, armed with five distal setae, four plumose and one naked and shorter, and ornamented with a row of spinules laterally. Palp armed with three terminal and one subterminal setae, all plumose.

Maxilla 3-segmented (Figs. 2g, 4d). Praecoxa bearing long flaccid element medially, possibly an aesthetasc; coxa unarmed and claw-like basis bearing small hyaline process proximally in axil. Claw surface with minute spinules arranged irregularly in medial part, armed with 1 very small seta at about one half length laterally and with rows of minute spinules distally.

Maxilliped 5-segmented (Fig. 2h). First segment with small inner distal seta and patch of fine spinules. Second segment elongate and slender with spinules distally and laterally. Third segment short, with three setae, two of them naked. Fourth segment armed with one plumose seta. Fifth segment ornamented with patches of small spinules on inner margin and armed with one subapical setae plumose only on outer edge. Terminal claw nearly three times longer than the fifth segment, $107 \mu \mathrm{m}$ long, ornamented with rows of minute spinules.

Swimming legs 1-4 biramous (Figs. 3a-d), with 3segmented rami. Intercoxal sclerite present in legs 1-4 and except in leg 4 , ornamented with patches of spinules. Spine and seta formula.

Table 1

\begin{tabular}{lllll}
\hline & Coxa & Basis & Exopod segments & Endopod segments \\
\hline Leg 1 & $0-1$ & $1-1$ & I-1;I-1;III,4 & $0-1 ; 0-2 ; 1,2,3$ \\
Leg 2 & $0-1$ & $1-0$ & I-1;I-1;III,I,4 & $0-1 ; 0-2 ; 1,2,3$ \\
Leg 3 & $0-1$ & $1-0$ & I-1;I-1;III,I,4 & $0-1 ; 0-2 ; 1,1+\mathrm{I}, 3$ \\
Leg 4 & $0-1$ & $1-0$ & I-1;I-1;III,I,4 & $0-1 ; 0-2 ; 1,1+\mathrm{I}, 2$ \\
\hline
\end{tabular}

Coxae of all legs ornamented with spinules rows laterally, as figured, and in leg 3 also with spinules in the margin. Inner coxal seta is plumose in legs $1-3$ and reduced and naked in leg 4. Except in leg 2, basal seta of all legs long and naked. Posterior surface of legs 1-4 with minute spinules (Fig. 4d).

Most of the outer spines of all exopodal segments bilaterally serrate, terminal exopodal element setiform in leg 1, spiniform in legs 2-4 serrate laterally and with setules medially or distally. Outer margins of exopodal and endopodal segments with setules.

Leg 5 (Fig. 1d) with protopodal segment incorporated into somite, with outer seta located dorsally ornamented with spines at base, exopod slender, more than two times longer than wide, ornamented with spinules and armed with two plumose setae and one naked seta.

\section{Adult male}

Body cyclopiriform with broad prosome as for female (Fig. 5a). Total length, excluding caudal setae, $660 \mu \mathrm{m}$ (645-675 $\mu \mathrm{m})$; (all measurements based on three specimens). Ratio of length of prosome to that of urosome 1.93:1. Ratio of lenth to width prosome 1.5:1. Urosome (Figs. 4f, 5b) consisting of five articulating units: leg 5bearing somite, genital somite and three free abdominal somites. Posterior margins of all somites ornamented with hyaline frills with serrated free margins. Surface of urosomal somites ornamented with fine spinules. Some spinules present also on dorsal surface of fifth pedigerous somite. Genital somite about 1.5 times wider than long, bearing genital apertures postero-laterally on ventral surface (Fig. 5b). Three postgenital somites from anterior to posterior $29.5 \times 66 \mu \mathrm{m}, 25 \times 61.3 \mu \mathrm{m}$, and $41 \times 52 \mu \mathrm{m}$. Caudal ramus 1.7 times longer than wide, armed as in female.

Appendages as for female except antennules, maxillipeds and fifth and sixth legs. Antennule (Fig. 5c) 17-segmented, geniculate; segmental fusion pattern as follow: 1(I), 2(II), 3(III), 4(IV), 5(V), 6(VI), 7(VII), 8(VIII), 9(IXXII), 10(XIII), 11(XIV), 12(XV-XVI), 13(XVII), 14(XVIII), 15(XIX-XX), 16(XXI-XXIII), 17(XXIVXXVIII). Geniculation located between segments 15 (XIX-XX) and 16 (XXI-XXIII). Segments 1-8 each with 2 setae; segment 9 with 8 setae; segments 10,11,13,14 each with 2 setae, segments 12 and 15 with 4 setae; segment 16 with 4 setae plus one aesthetasc, segment 17 with 11 setae. Segment 10(XIII) reduced, partly overlapped by distal expansion of compound segment 9 (IX-XII).

Maxilliped (Fig. 5d) 5-segmented; comprising short syncoxa, long basis and distal subchela consisting of three free endopodal segments armed with distal clawlike element. Syncoxa with patch of fine spinules at proximal angle and one medial seta; basis with one minute seta, one small tooth-like process in proximal half of medial margin and some patches of fine spinules in medial and distal half of external margin. First endopodal segment bearing three setae, two of them 

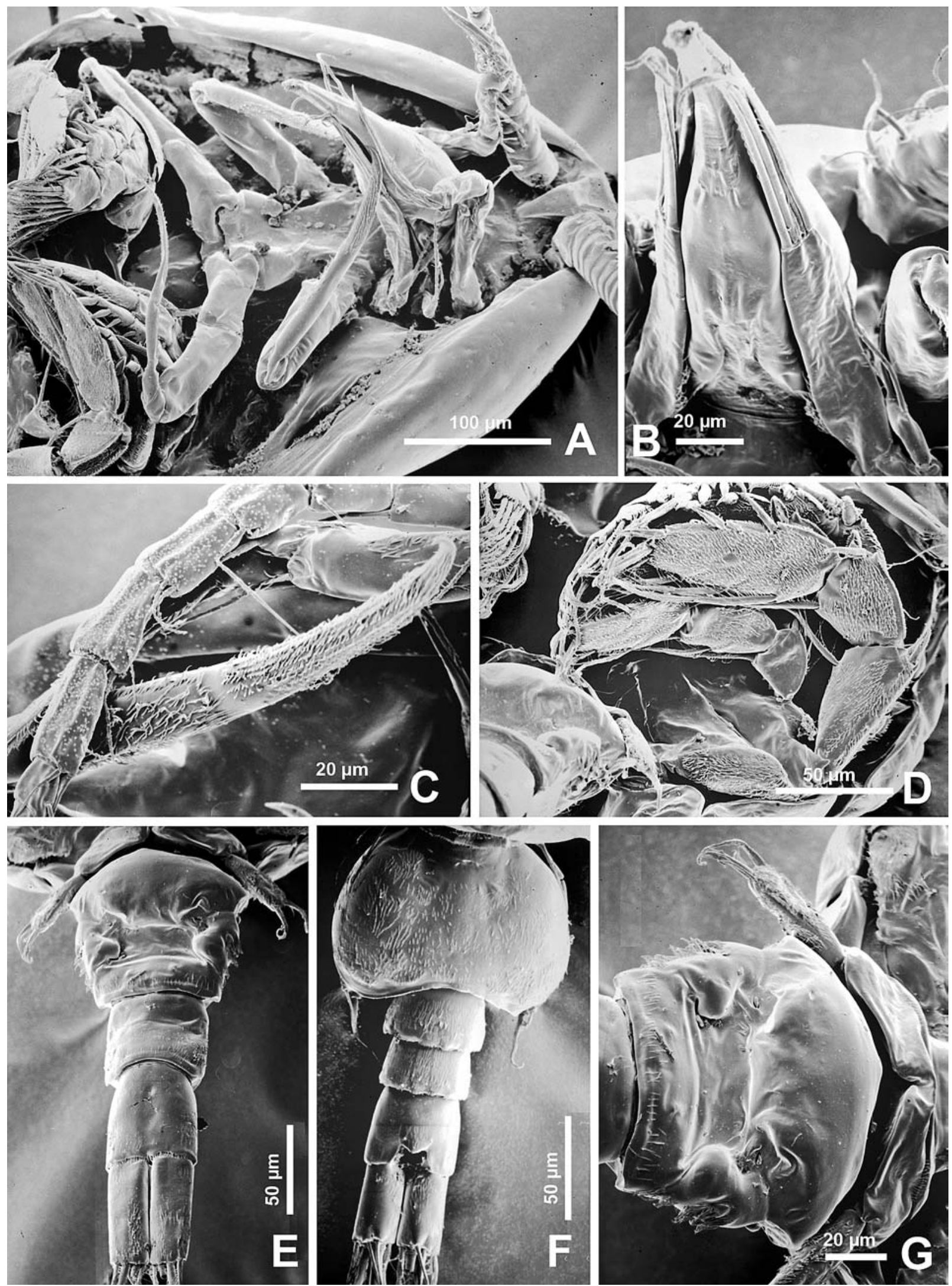

Fig. 4 Asterocheres hirsutus sp. nov. Female: a, general view of the oral appendages; $\mathbf{b}$, oral cone and maxillule; $\mathbf{d}$, posterior surface of leg 4 ; e, ventral view of urosome; $\mathbf{g}$, ventral view of the genital double-somite. Male: $\mathbf{c}$, detail of the distal segment of the maxilla and last antennular segment; f, dorsal view of urosome 
naked. Second endopodal segment armed with one plumose seta. Third endopodal segment bearing long terminal claw plus additional apical plumose seta. Clawlike element with rows of minute spinules.

Leg 6 (Fig. 5b) postero-ventral flap on genital somite bearing two subequal seta, the outer naked and ornamented with rows of fine spinules.

\section{Etymology}

The species is named from the Latin hirsutus (= hirsute, hairly), alludes to the numerous spinules and setules present on the surface of this species.

\section{Discussion}

The genus Asterocheres contains a large number of species which can be divided into two groups (Boxshall and Huys 1994). The smaller group, to which the new species belongs, is characterised by females with a 21 -segmented antennule and the larger group is characterised by females having an 18- to 20-segmented antennule. According to Kim (2004), a total of ten valid species are included in the first group: $A$. bulbosus Malt, 1991; A. flustrae Ivanenko and Smurov, 1997; A. jeanyeatmanae Yeatman, 1970; A. lunatus Johnsson, 1998; A. minutus (Claus, 1889); A. reginae Boxshall and

Fig. 5 Asterocheres hirsutus sp. nov. Male, a, habitus, dorsal; b, urosome, dorsal; c, antennule; d, maxilliped

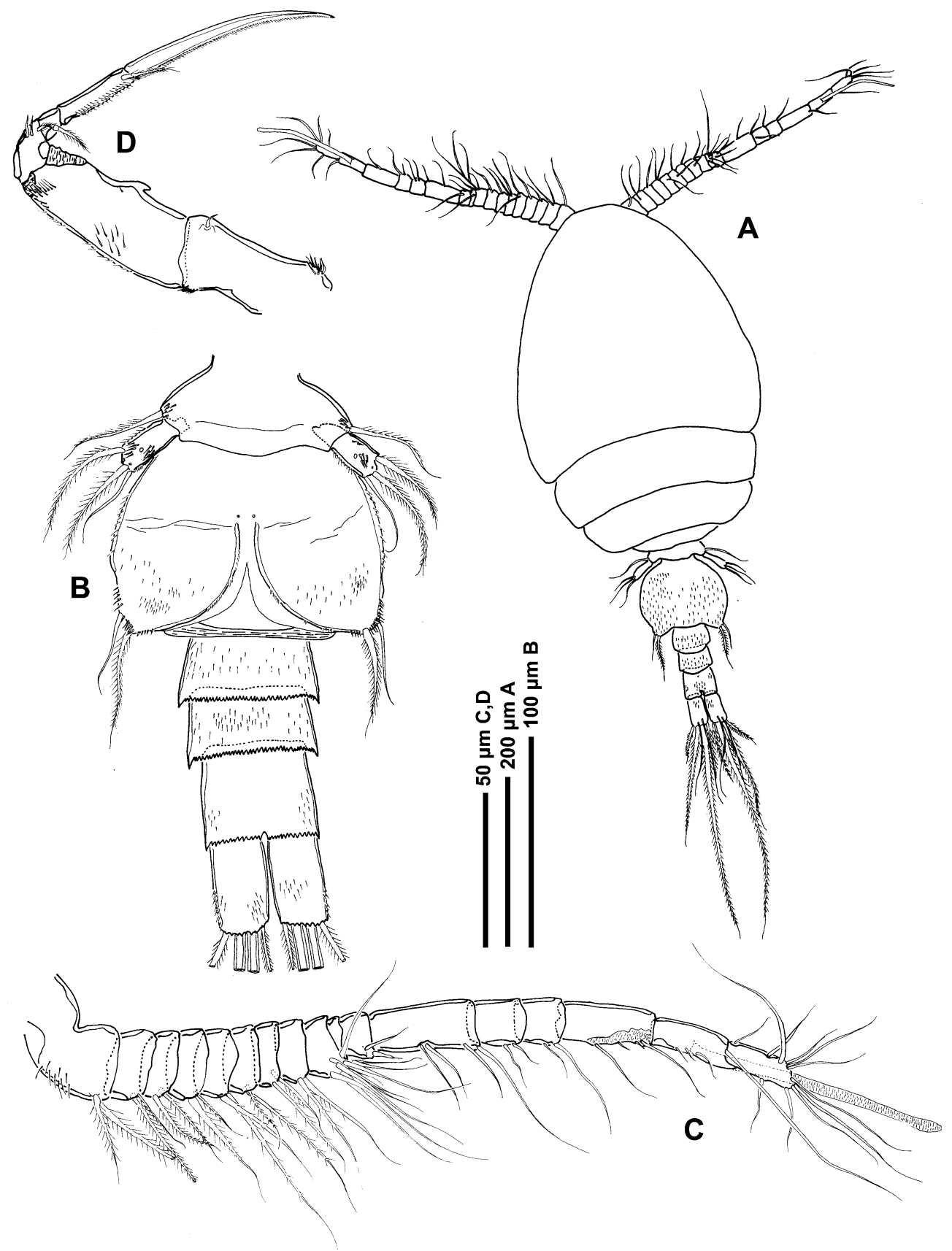


Huys, 1994; A. suberitis Giesbrecht, 1899; A. tenuicornis Brady; A. violaceous (Claus, 1889) and A. urabensis Kim, 2004. Ivanenko and Smurov (1997) pointed out that $A$. aesthetes Ho, 1984 was described in the text as having a 19-segmented antennule in the female which is discordant with the presence of 21 segments on the figure. However, Ho (personal communication 2003) has established that the antennule of $A$. aesthetes has 19 segments with the terminal segment indistinctly divided into two segments.

Among these species only three, A. aesthetes, $A$. flustrae and $A$. reginae, have an aesthetasc on the proximal part of the syncoxa of the maxilla, as found in A. hirsutus. Boxshall and Huys (1994) considered this character as unusual in the genus since only two species, $A$. aesthetes and A. reginae possessed this character (see Ho 1984, Boxshall and Huys 1994). The discovery of this aesthetasc in a new species of Asterocheres, A. flustrae, and in other three genera of Asterocheridae, Chelacheres Humes, 1989, Sinopontius Boxshall, 1990 and Inermocheres Boxshall, 1990, strongly suggested that this characteristic is probably more common within this family, as was pointed out by Boxshall and Huys (1994), but it has been overlooked (Ivanenko and Smurov 1997). This is the main reason for not using this characteristic to distinguish the new species from its congeners in the present paper.

Asterocheres hirsutus sp. nov. may be separated from all congeners with 21-segmented antennule by the shape of its maxillule, with the endite being nearly five times longer than the palp and the caudal rami 2.5 times longer than wide. Furthermore, A. bulbosus, A violaceus and $A$. minutus differ from $A$. hirsutus in their possession of 1 -segmented mandibular palp. A. suberitis has a 2 -segmented endopod in the antenna, instead of the 3 -segmented endopod present in the antenna of $A$. hirsutus. A. tenuicornis is also readily distinguished from the new species, and all its congeners, by its very elongate caudal rami. A. jeanyeatmanae possesses only two setae in the free segment of leg 5, instead of the three setae of A. hirsutus. A. lunatus has four setae in the inner lobe of maxillule and the formula (1-0) in the basis of leg 1 , by contrast, $A$. hirsutus has five distal setae in the endite of maxillule and the formula (1-1) in the basis of leg 1 . The extremely flattened prosome of $A$. reginae serves to separate it from the new species. The maxilliped is 6-segmented in A. flustrae and 5-segmented in A. hirsutus. The claws of the antenna, maxilla and maxilliped of $A$. urabensis are smooth; however, in A. hirsutus they are densely hairy.

Acknowledgements The authors would like to thank the officers and the crew of the RV Polarstern and many colleagues for their help on board during the EASIZ-III cruise. Special thanks are addressed to Josep Maria Gili and Wolf Arntz who made possible the participation in the Antarctic cruise where the present material was collected. We would like to thank J.-S. Ho for his helpful comments during the preparation of this paper, and Nuria Teixido for her valuable assistance in consulting some bibliographic references.Support for this work was provided by the Spanish CICYT projects ANT98-1739-E, ANT99-1608-E, REN2001-4920-E/ANT, and REN 2001-4269-E/ANT.

\section{References}

Arntz WE (1997) Investigación antártica en biología marina: situación actual, proyectos internacionales y perspectivas. Bol $\mathrm{R}$ Soc Esp Hist Nat (Secc Biol) 93(1-4):13-44

Boxshall GA, Huys R (1994) Asterocheres reginae, a new species of parasitic copepod (Siphonostomatoida: Asterocheridae) from a sponge in Belize. Syst Parasitol 27:19-23

Galéron J, Herman RL, Arnaud PM, Arntz WE, Hain S, Klages M (1992) Macrofaunal communities on the continental shelf and slope of the southeastern Weddell Sea, Antarctica. Polar Biol $12: 283-290$

Ho J-S (1984) Copepoda associated with sponges, cnidarians and tunicates of the sea of Japan. Rep Sado Mar Biol Stat Niigara Univ 14:23-61

Huys R, Boxshall GA (1991) Copepod evolution. The Ray Society, London

Ivanenko VN, Smurov AV (1997) Asterocheres flustrae n. sp. (Copepoda: Siphonostomatoida: Asterocheridae) associated with Flustra foliacea L. (Bryozoa) from the White Sea. Syst Parasitol 38:111-130

Johnsson R, Bustamante AO (1997) Monocheres cagarrensis sp. nov. (Copepoda, Siphonostomatoida) from Brazil. Crustaceana 70(8):894-900 